matical one without lowering the standard ?" His own preferences are for logic, economics and psychology, or for a training in creative work-design or construction. Possibly all these could be combined with some engineering studies; but almost inevitably the length of time required to achieve a reasonable standard would be longer than is needed for a training in the mathematical technique.

He explained the practice of the University of Durham in admitting a small number of students to the engineering courses each year who had the Higher National Certificate in Mechanical Engineering as their qualification for admission. Some of these students had been very successful, but the greatest difficulty they presented was how to select the best of those who apply for the small number of places available.

Those who advocated making management a closed profession like the medical profession wish to see university degrees in management made a compulsory requirement for anyone holding a managerial position. The universities have not responded enthusiastically to the suggestion that they should provide courses in management, and there is little or no provision for those who intended to make management studies their postgraduate work.

The best solution Prof. Burstall could offer for bringing together technology and the humanities in further education was a combination of four main studies over four years: (1) philosophy (logic and ethics); (2) economics (including the principles of accounting); (3) the principles of physical science (mostly applied science, including machine drawing and some laboratory work-taught with the minimum of mathematics); and (4) biological science, with emphasis on public health, safety and industrial psychology. Such a training ought to make the successful candidate worthy of a bachelor's degree.

Mr. K. R. Evans and Mr. B. J. Crowther were concerned not only with university graduates in engineering but also with other apprentices, including trade apprentices, to whom further education is given during their works apprenticeship. They asserted that practical experience in the humanities is gained by apprentices in the course of their human relation. ships in the works, especially in running the apprentice associations. These are administered by elected apprentices who receive only guidance from the stafi of the works education department. They administer the social, recreational and athletic activities of the association and produce their own magazine. Senior apprentices also take part in assessing applicants for apprenticeship when they visit the works for interview.

Messrs. Evans and Crowther also described the teaching of social and economic history as valuable to apprentices, and said it is best approached through the history of engineering, particularly that of the local industrial area. The selection of subjects for further education of the manual or unskilled worker is a difficult problem. "Those industries in which the manual operations are repetitive and whose management grades are less likely to be derived from those who started their working life as manual workers, will find more difficulty in instigating formal or informal studies in cultural and non-technical sub. jects, not necessarily because the workers lack intelligence or even basic education, but because there exists no ready-made study interest on which to build.'

They recommended sending young workers for a short period for a residential course, such as that given at Rugby School. The selection should be made not from those who would be a credit to the company, but from the type of young person who is in need of just such an experience.

During the ensuing discussion, it was suggested that justice had not been done to the technical colleges, which had scarcely been mentioned, though in many places they are becoming local colleges of education rivalling the universities in the variety of subjects taught. One principal of such a college thought they did much to bring the humanities and technology together in further education, and appealed for a wider development of residential facilities, so that the technical colleges could extend this side of their work. There was general agreement that the conventional type of engineering course does not develop the qualities most needed in administrative work, and one speaker referred to the present diffi. culty of finding suitably qualified men to occupy posts in the higher levels of administration, particularly in the nationalized undertakings.

There was a marked difference of opinion about interesting students of technology in art, music and literature. Some had been unsuccessful in their attempts to do this, and had given it up; another referred to outstanding success in this endeavour achieved by the Scandinavian colleges. One speaker asserted that pure science is just as effective as logic in teaching a student how to think. This was challenged by a later speaker, who referred to the report on "Transfer of Training" published by Section $\mathrm{L}$ of the British Association in 1930.

Several speakers mentioned that students of languages and of the arts would be all the better for some knowledge of technological matters.

\section{CONVERSION OF MANNITOL AND SORBITOL INTO DULCITOL}
By DR. P. BLADON/And DR. L. N. OWEN
Imparial College of Sglence and Technology, London
DR. W. G. OVEREND and DR. L. F. WIGGINS
A. E. Hills yaboratories, University, Birmingham
$\mathrm{N}$ a recept publication ${ }^{1}$, the preparation of $1: 6$. 1 dithionannitol is described. In subsequent attempty to obtain this dithiol by other routes, two of us (L. N. O. and P. B.) have treated $1: 6$-ditosyl $2: 5$ Aiacetyl 3:4-isopropylidene mannitol ${ }^{2}$ with potassium thioacetate in boiling acetone, a reaction which has been shown ${ }^{3}$ to result in the replacement of tosyloxy- by acetylthio-groups. Removal of the acetyl and acetone residues from the product gave crude 1 : 6-dithiomannitol, m.p., 120-135 ${ }^{\circ}$, the hexa- acetyl derivative of which had m.p. 109-111 $[\alpha]_{D}^{10^{\circ}}+85 \cdot 0^{\circ}$ (all rotations in chloroform). This was clearly not identical with the previously described hexa- acetyl 1:6-dithiomannitol of m.p. $188^{\circ},[\alpha]_{D}^{18^{\circ}} \pm 0^{\circ}$.
The latter material had been prepared by the action of potassium thioacetate on the so-called tetra-acetyl 1:6-dibromo 1:6-dideoxymannitol of Vogel ${ }^{4}$, and since it was unlikely that any abnormal reaction could have occurred at that stage, it was decided to investigate the structure of Vogel's 


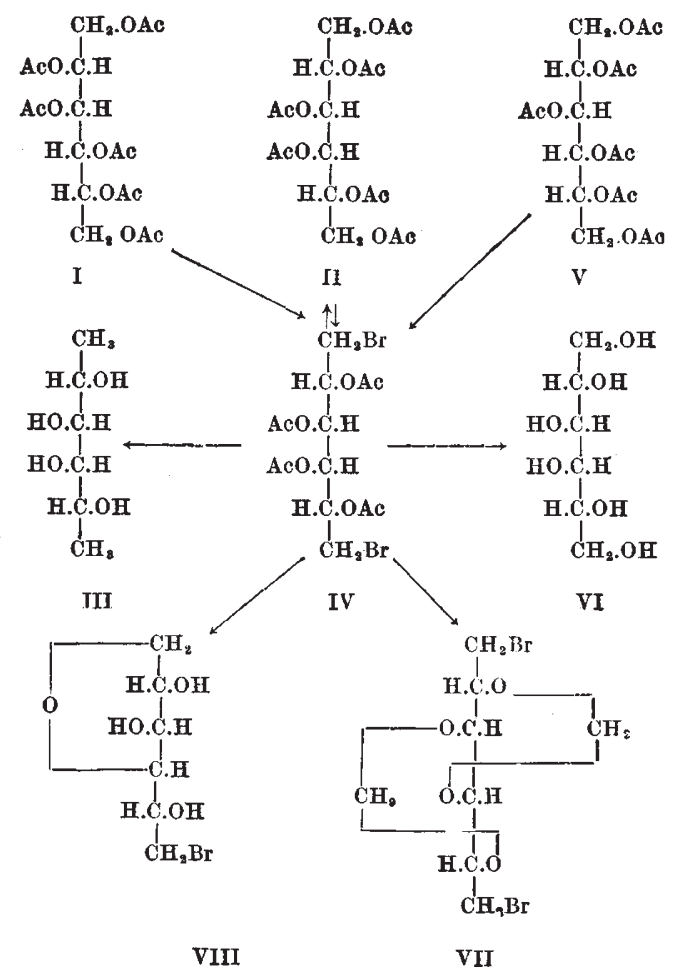

dibromide. This compound (m.p. 197-199 $)$ was prepared by Vogel's method (action of hydrogen bromide in acetic acid on hexa-acetyl mannitol (I) for several months at room temperature), and by the more convenient method of warming the reaction mixture for ten hours at c. $40^{\circ}$. Particular care was taken to ensure the purity of the mannitol used for the preparation of the hexa-acetate, the commercial product being purified by regeneration from its triisopropylidene derivative. The dibromide so obtained, on reaction with potassium acetate in acetic acid acetic anhydride solution, gave hexa-acetyl dulcitol (II), m.p. and mixed m.p. $168-169^{\circ}$, in more than 90 per cent yield. Furthermore, hydrogenation of the dibromide over Raney nickel gave tetra-acetyl 1:6-dideoxydulcitol, m.p. $182-184^{\circ}$ (found : $\mathrm{C}$, $52 \cdot 8 ; \mathrm{H}, 7 \cdot 2 . \mathrm{C}_{14} \mathrm{H}_{22} \mathrm{O}_{8}$ requires $\mathrm{C}, 52 \cdot 8 ; \mathrm{H}, 7 \cdot 0$ per cent), which on deacetylation yielded the known 1:6-dideoxydulcitol (III) ${ }^{5}$, m.p. $185^{\circ}$ (diisopropylidene derivative, m.p. $63-64^{\circ}$ ), whereas with sodium iodide in acetone solution the dibromide furnished tetra-acetyl 1 : 6-di-iodo $1: 6$-dideoxydulcitol, m.p. 188-190 (decomp.), (found : C, 29.4 ; $\mathrm{H}, 3.8$. $\mathrm{C}_{14} \mathrm{H}_{20} \mathrm{O}_{8} \mathrm{I}_{2}$ requires $\mathrm{C}, 29.5 ; \mathrm{H}, 3.5$ per cent). This evidence proves beyond doubt that Vogel's dibromide is actually tetra-acetyl $1: 6$ dibromo 1:6-dideoxydulcitol (IV), and it must therefore be identical with the compound described by Wolfrom et al. ${ }^{6}$. The optical rotation recorded by Vogel is erroneous; the dibromide and all the above compounds derived from it are optically inactive, in conformity with the dulcitol configuration. The original '1 : 6-dithiomannitol' obtained from Vogel's dibromide is therefore $1: 6$-dithiodulcitol.

In view of these rather surprising results, it appeared to be very probable that the compound, m.p. $196^{\circ}$, prepared by the action of hydrogen bromide in acetic acid on hexa-acetyl sorbitol (V), and assumed to be a sorbitol derivative ${ }^{1}$, also had the same structure (IV). This proved to be so, the product being identical with that obtained from hexa-acetyl mannitol (I); the same substance was also obtained by a similar reaction on hexa-acetyl dulcitol (II). The yields of (IV) from the hexaacetates of mannitol, sorbitol and dulcitol were respectively 23,25 and 58 per cent.

A similar conclusion with regard to the constitution of the Vogel dibromide has been reached independently (by L. F. W. and W. G. O.) in the Chemistry Department of the University of Birming. ham. It was found that the dibromide prepared according to the conditions of Vogel contained two bromine groups attached to primary carbon atoms, since reaction with sodium iodide in acetic anhydride solution rapidly took place (45 min.) with the formation of tetra-acetyl $1: 6$-di-iodo $1: 6$-dideoxyhexitol $(A)$ (m.p. $188-189^{\circ}$ ). The acetyl residues were also replaceable by two methylene groups on treating the original dibromide with paraformaldehyde and concentrated sulphuric acid. Dimethylene 1: 6-dibromo $1: 6$-dideoxyhexitol $(B)$ was formed. When the Vogel dibromide was treated with sodium methoxide, a small yield of a crystalline anhydro hexitol monobromohydrin (m.p. $143^{\circ}$ ) was obtained, and this proved to be identical with the dulcitan monobromohydrin $(C)$, which Maquenne? describes as being obtained by the hydrolysis of dulcitol dibromohydrin. Final proof that the Vogel dibromide was indeed tetra-acetyl $1: 6$-dibromo $1: 6$-dideoxydulcitol was obtained when it was hydrolysed with aqueous hydrobromic acid. Dulcitol (VI) itself was isolated and characterized by means of its melting point and by conversion to hexa-acetyl dulcitol. Thus $(A)$ is tetra-acetyl $1: 6$-di-iodo $1: 6$-dideoxydulcitol, and $(B)$ is dimethylene $1: 6$-dibromo 1 : 6-dideoxydulcitol, probably represented by (VII). The dulcitan monobromohydrin $(C)$ is probably 1 : 4-anhydro 6-bromo 6-deoxydulcitol (VIII).

The remarkable conversion of the mannitol and sorbitol configurations directly into that of dulcitol has not been previously reported in the literature and is of considerable theoretical interest. It sug. gests that, under the conditions of this reaction, Walden inversion can occur at all the asymmetric centres, giving rise to a mixture of hexitol derivatives of various configurations. The ready isolation of the tetra-acetyl 1:6-dibromo $1: 6$-dideoxydulcitol is undoubtedly due to its relative insolubility, by virtue of which it is precipitated during the reaction in almost pure form. It is probable that the liquid portion of the reaction mixture contains hexitol derivatives of other configurations. The fact that Vogel quoted $[\alpha]_{D}^{18^{\circ}}+10 \cdot 26^{\circ}$ for his dibromide may possibly be explained by the presence of these isomers as impurities in his material.

It is not unlikely that the tetra-acetyl dichloro dideoxymannitol of Fischer and Armstrong (m.p. $214^{\circ}$ ), obtained by the action of liquid hydrogen chloride on hexa-acetyl mannitol, is a dulcitol derivative. This is certainly different from the tetra. acetyl $1: 6$-dichloro $1: 6$-dideoxymannitol of Griner ${ }^{2}$, and this material must be a true mannitol derivative because it has been obtained simply by the acetyl. ation, under mild conditions, of $1: 6$-dichloro $1: 6$ dideoxymannitol, which, by the work of Haworth and Wiggins ${ }^{10}$, is without doubt a mannitol derivative.

Further work on this interesting reaction is now in progress, and fuller details will be published elsewhere. One of us (P. B.) wishes to thank the Depart- 
ment of Scientific and Industrial Research for a maintenance grant, and two of us (L. F. W. and W. G. O.) wish to thank the Colonial Products Research Council for financial support.

${ }^{1}$ Evans, R. M., Fraser, J. B., and Owen, L. N., J. Chem. Soc., 248 (1949)

2Wiggins, L. F., J. Chem. Soc., 386 (1946).

${ }^{3}$ Chapman, J. H., and Owen, L. N., unpublished work.

"Vogel, H., Ber., 71, 1272 (1938)

- Ness, A. T., Hann, R. M., and Hudson, C. S., J. Amer. Chem. Soc. 64, 984 (1942).

'Wolfrom, M. L., Burke, W. J., and Waisbrot, S. W., J. Amer. Chem. Soc., 81, 1828 (1939).

'Maquenne, L., "Les Sucres et Principaux Dérivés", 126 (Georges Carré et C. Naud, Paris, 1900).

${ }^{8}$ Fischer, E., and Armstrong, E. F., Ber., 35, 842 (1902).

- Griner, G., Ann. Chim., (6), 26, 380 (1892).

${ }^{10}$ Haworth, W. N., and Wiggins, L. F., J. Chem. Soc., 58 (1944).

\section{ECLIPSE OBSERVATIONS OF SOLAR RADIATION AT A WAVE-LENGTH OF $50 \mathrm{CM}$.}

By W. N. CHRISTIANSEN, D. E. YABSLEY and
B. Y. MLLS
Radiophysics Laboratory, Commonwealth Scientific and
Industrial Reseay h Organization, Australia HE solar eclpse of November 1, 1948, was
visible in it partial phases over most of Aus tralia. Observations of radio-frequency radiation at a wave-length of $50 \mathrm{~cm}$. were made at three sites to determine the distribution of radio brightness over the solar Aisk and also to investigate possible polarization ffects associated with solar magnetic fields.

Prefious work ${ }^{1,2,3}$ at decimetre wave-lengths has suggested that the radiation may be divided into : (a) a thermal component from the 'quiet' sun, and (b) a component which is correlated with sunspot area. Theoretical considerations ${ }^{4}$, based on the probable existence of temperatures around $10^{\circ}{ }^{\circ} \mathrm{K}$. in the corona, suggest that the first component should show 'limb-brightening' at these wave-lengths. A solar eclipse provides an opportunity of testing this prediction. It has been suggested ${ }^{4}$ also that a general magnetic field on the sun should produce an inequality in the circularly polar. ized thermal components of the radiation from each hemisphere. The circumstances of this eclipse were such that one hemisphere only was visible at the maximum phase, and this favoured the detection of such an effect.

The flux density of radio-frequency power from the sun was measured during the eclipse at Sydney (New South Wales), Rockbank (near Melbourne, Victoria), and Strahan (Tasmania). The results are shown in Fig. 1. At each place, departures from a smooth curve were found in the record.
These appeared to be caused by the eclipsing on the sun of small areas that had a greater radio brightness than their background. A similar effect has been noted at a wave-length of $10.7 \mathrm{~cm}$. by Covington ${ }^{b}$.

The positions of these small bright areas were determined as follows. The times at which the magnitude of the power flux density changed most rapidly were found from the records. It was inferred that at these times the edge of the moon passed over a bright area. The apparent positions of the edge of the moon's disk with respect to the solar disk at these times were known for each station, and hence the position of each bright area could be indicated by a circular arc. At the three observing stations the apparent path of the moon was markedly different, and arcs for one station therefore inter. sected those for the other observing stations. The point of intersection of appropriate arcs indicated the position of a bright area. Such intersections are shown in Fig. 2. Of the eight bright areas denoted by full circles in Fig. 2, seven were found close to the positions of optical features on the disk : (a) three coincided in position with visible sunspot groups (three other sunspot groups showed no associated bright area); (b) three were found close to the positions occupied by sunspot groups 27 days previously; (c) one was found at a distance of roughly $1.7 \times 10^{5} \mathrm{~km}$. outside the limb of the disk and close to a solar prominence (one other prominence which was eclipsed showed no associated bright area).

In two instances the interpretation of the inter sections was ambiguous and the location corresponding to the closest intersection was selected. One doubtful location is shown enclosed by the dotted circle on the left of Fig. 2. This area was eclipsed only at Strahan and is defined by the intersection of two ares only, one corresponding to the covering and one to the uncovering of the area.

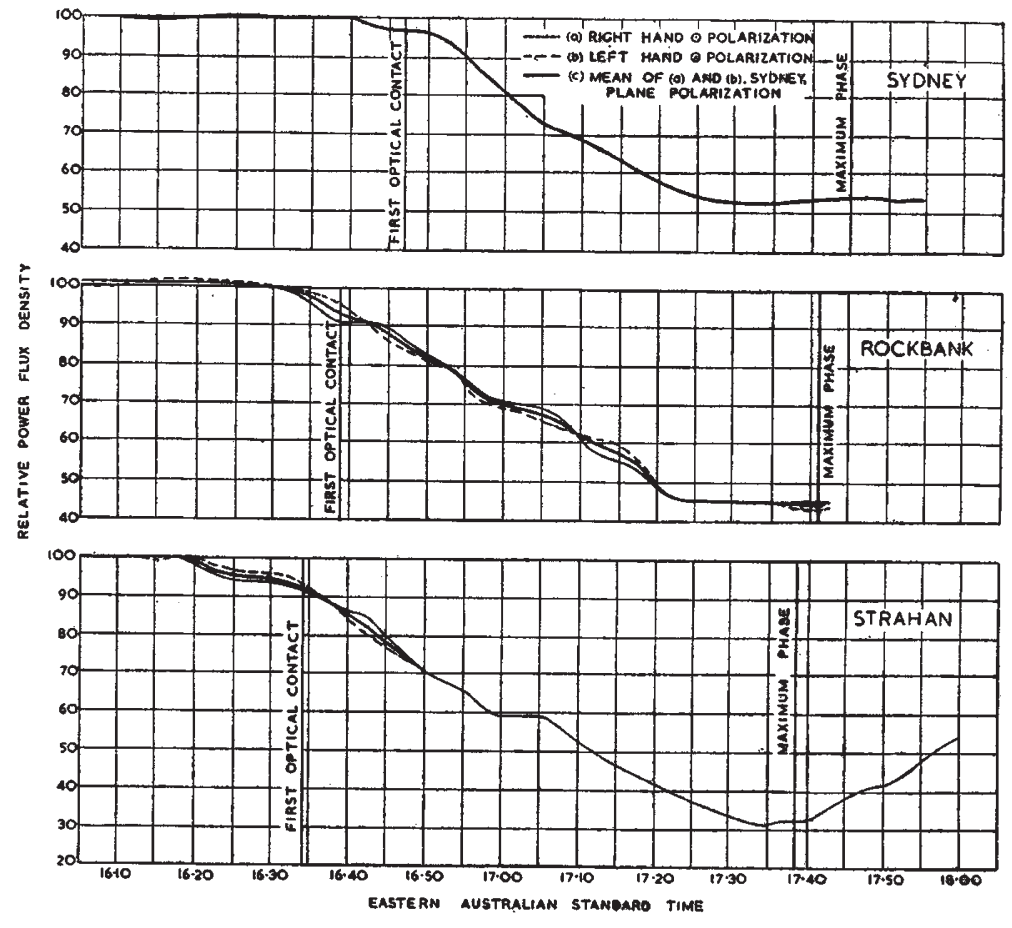

Fig. 1. Records taken at three places showing changes in power flux-density during the eclipse 